\title{
THE SIGNIFICANCE OF COLOR CHANGES IN OXIDASE REAGENTS
}

\author{
G. B . R E E D
}

Our knowledge of the oxidases has been derived almost entirely from the study of their action upon compounds which change color on oxidation. It is customary to employ for this purpose compounds which do not oxidize spontaneously (or do so very slowly) when exposed to the air in dilute solutions, but which when brought into contact with living tissues (or extracts of tissues) exhibit a change of color.

The formation of such colored compounds as a result of oxidase action has afforded a ready method of determining the distribution of these ferments. The behavior of the various indicators when placed in contact with different tissues has also led to the conclusion that the oxidases may be divided into several more or less definite classes.

The rate of oxidase action and the relative efficiency of different preparations of oxidases have also been determined by measuring the intensity of the color produced in solutions of such indicators. ${ }^{\mathrm{r}}$

Valuable as these methods have been, they have given no indication of the amount of oxidation which has taken place. Thus, when an oxidase causes a change of color in one of these reagents we have no idea of the amount of oxidation which this reaction represents. Moreover, it often has been assumed that the appearance of a definite color in any of these reactions, acted upon by the oxidases, represents similar amounts of oxidation. For example, an oxidase capable of bringing about sufficient oxidation to give a distinct blue color in a solution of gum guaiac has been considered about as efficient as one capable of producing enough purpurogallin to give a distinct yellow color in a solution of pyrogallol.

Inasmuch as the greater part of the results obtained by workers on oxidase reactions depend upon these color changes, it is important

${ }^{r}$ The various methods employed in colorimetric determinations of the rate of oxidase action have recently been reviewed by FOA, Biochem. Zeit. 2:382-399. 1908; and also by Bunzell, Bull. no. 238. Bur. Pl. Ind., Washington. i9i r.

Botanical Gazette, vol. 6I] 
to have a clear conception of their quantitative as well as of their qualitative meaning. The following experiments present such quantitative values.

Solutions of a number of the oxidase reagents in most common use were made up in equivalent concentrations, $\mathrm{O}$. I $\mathrm{M}$ in water (in the case of aloin and alpha napthol in 50 per cent alcohol, as they are only slightly soluble in water). As gum guaiac consists of a number of compounds in unknown proportions, a 2 per cent solution of the resin in 50 per cent alcohol was taken.

Two beakers, each containing roo cc. of one of these solutions, were placed in a uniform light in such a position that the colors of the solutions could be accurately compared. A standard potassium permanganate solution ${ }^{2}$ was then added to one beaker in sufficient amount to cause a definite change in color due to oxidation, as compared with the beaker to which no addition was made. ${ }^{3}$

Table I indicates the amount of permanganate required to produce the first perceptible change of color in the several reagents tested. The last column of the table also gives the amount of oxygen used in the oxidation as calculated from the amount of permanganate required.

TABLE I

\begin{tabular}{|c|c|c|}
\hline Solution; roo cc. o. I M & $\begin{array}{l}\text { Amount (cc.) of } \\
\text { standard } \mathrm{KMnO}_{4} \\
\text { required to produce } \\
\text { a definite color }\end{array}$ & $\begin{array}{c}\text { Gram atoms of } \\
\text { oxygen required to } \\
\text { produce a definite } \\
\text { color }\end{array}$ \\
\hline 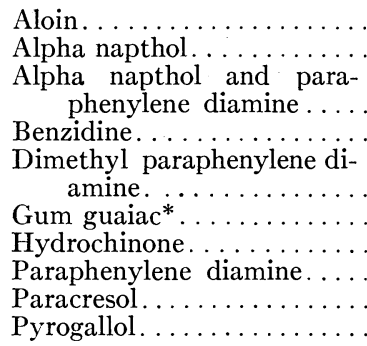 & $\begin{array}{l}2 \\
3 \\
\\
0.5 \\
\text { trace } \\
\text { IO } \\
\text { I } \\
\text { I } \\
9\end{array}$ & $\begin{array}{l}\text { I. } 2 \times 10^{-6} \\
2.5 \times 10^{-6} \\
2.5 \times 10^{-6} \\
3.7 \times 10^{-6} \\
5.1 \times 10^{-6} \\
\text { trace } \\
\text { I. } 2 \times 10^{-5} \\
\text { I. } 2 \times 10^{-6} \\
\text { I. } 2 \times 10^{-6} \\
\text { I. } 1 \times 10^{-5}\end{array}$ \\
\hline
\end{tabular}

* A 2 per cent solution was used, as the molecular weight is not known.

${ }^{2}$ Of this solution $80 \mathrm{cc}$. was exactly sufficient to oxidize ro cc. of o. I M oxalic acid.

3 Since in the oxidation of these reagents the potassium permanganate is reduced to a.colorless condition, its color can appear only after a sufficient amount is added to oxidize all of the reagent. Since this condition is not reached, the permanganate produces no color to obscure the color of the compounds produced by the oxidation. 
Similar results were obtained in the oxidation of the naturally occurring chromogens, although they cannot be stated in as definite a form. Equal amounts (25 gm. of fresh material) of tissue of apple, of potato, and of the stems of Vicia Faba were each crushed in $100 \mathrm{cc}$. of water and filtered rapidly. Enough of the standard permanganate was then added to each solution to give the first appearance of the chromogen color. Table II indicates the amounts of permanganate required and the amounts of oxygen which they represent.

TABLE II

\begin{tabular}{|c|c|c|}
\hline Water extract; Ioo cc. & $\begin{array}{l}\text { Amount (cc.) of } \\
\text { standard } \mathrm{KMnO}_{4} \\
\text { required to produce } \\
\text { chromogen color }\end{array}$ & $\begin{array}{l}\text { Gram atoms of } \\
\text { oxygen required to } \\
\text { produce chromogen } \\
\text { color }\end{array}$ \\
\hline 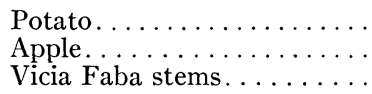 & $\begin{array}{l}9 \\
6 \\
4\end{array}$ & $\begin{array}{l}1.1 \times 10^{-5} \\
7.5 \times 10^{-6} \\
5.0 \times 10^{-6}\end{array}$ \\
\hline
\end{tabular}

These results indicate that the amount of oxidation necessary to produce the colored appearance in either the ordinary oxidase reagents or in the plant chromogens is exceedingly small. This, however, does not indicate that the oxidases are capable of producing only a small amount of reaction, for after the color appears the oxidation may continue without necessarily changing the color.

These observations also clearly indicate that the amount of oxidation necessary to produce a color in the various reagents varies over a wide range. But by this very simple method the different reagents may be calibrated so that the effects of the oxidases may be measured, and the oxidation necessary to produce a change of color in the presence of oxidases may be expressed in grams of oxygen required.

Laboratory of Plant Physiology

HARVARD UNIVERSITY 